\title{
تداعيات أزمة كورنا على تسوية المنازعات التجارية
}

\author{
ورقة بحثية \\ للمشاركة في المؤتمر العلمي الخامس \\ لكلية التجارة جامعة طنطا \\ بعنوان: أثر أزمة كورونا على الاقتصاد القومي المقترحات والحلول \\ المحور الثالث: الجوانب الاقتصادية
}

دكتور

عبدالله عبدالحي الصاوي

مدرس قانون المرافعات

كلية الشربعة والقانون بالقاهرة - جامعة الأزهر 


\section{بسم الله الرحمن الرحيم}

\section{مقدمة}

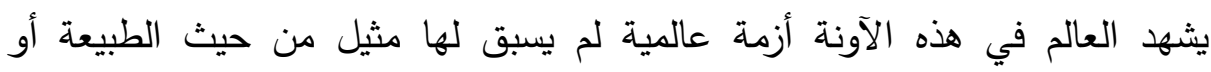

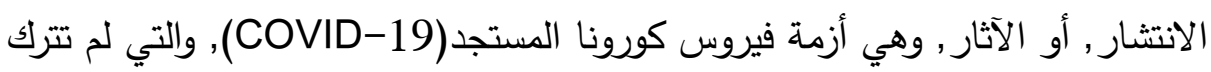

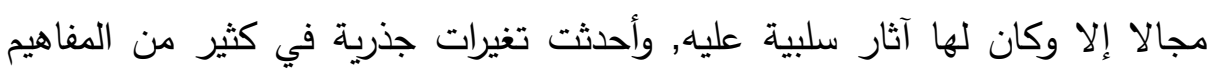
الثابتة والمستقرة في الوجدان الدولي. وقد كان ولا يزال لهذه الأزمة من الآثار على المجال التجاري ما يصعب حصره؛ وكان من نتاج ذلك حدوث العديد من المنازعات التجارية التي تتطلب تسوية تتقى لتانق

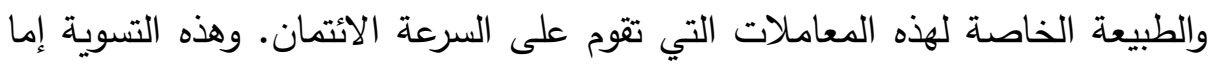
أن تكون اتفاقية عبر وسائل يتفق عليها أطراف المنازعة؛ وإما أن تكون قضائية يضطلع بها القضاء الرسمي في الدولة. ولا شك أن من أشد آثار الأزمة ما شهده العالم من حالات الإغلاق وتوقف حركة حركة

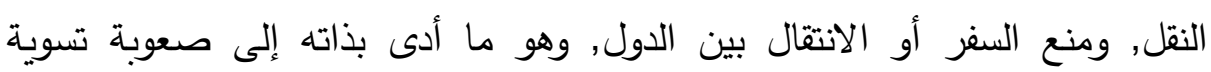
المنازعات التجارية بالوسائل التقليدية التي توجب الحضور المادين التول وهادي لأطراف المنازعة,

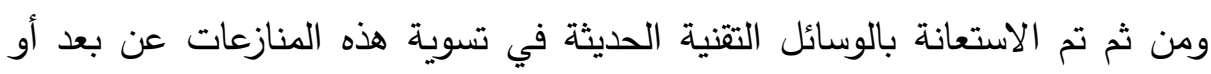
بوسائل إلكترونية. الإثكالية: تتجسد إثكالية هذه الورقة البحثية في تتاول أثر أزمة كورونا على تسوية

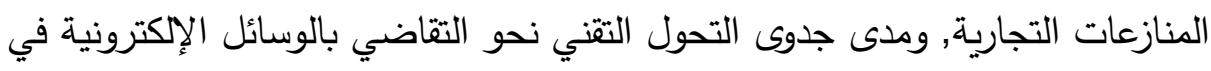
تسوية المنازعات التجارية. الأهمية:

تتمثل أهمية الموضوع في تتاوله لفكرة باتة ضرورية وأساسية في المجالين القضائي

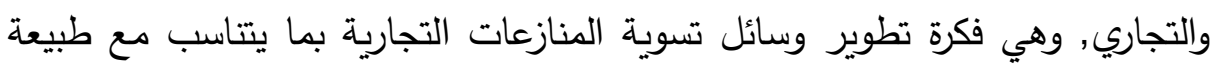
هذه المنازعات, ضمانا لفعالية هذه الوسائل, سيما في ظل أزمة كورونا المعاصرة.

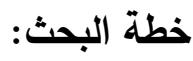

نتتاول موضوع البحث من خلال ثلاثة محاور؛ الأول: الآثار الاقتصادية لأزمة كورونا, والثاني: انعكاس الأزمة على التسوية الاتفاقية للمنازعات التجارية, أما الثالث:

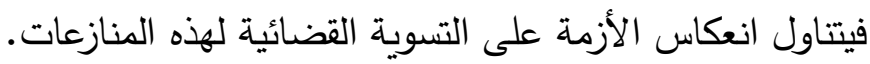




\section{مطلب تمهيدي}

\section{تداعيات الأزمة على الاقتصاد المحلي والعالمي}

أولا: أهم آثار الأزمة على الاقتصاد المصري:

سببت جائحة كورونا (COVID-19) العديد من التداعيات السلبية على الاقتصاد

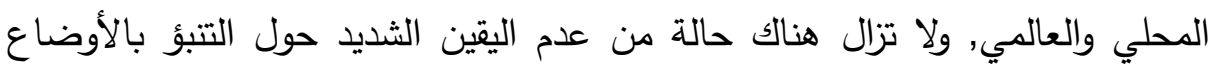

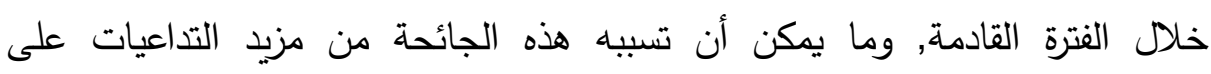
القطاعات الاقتصادية المختلفة. ورغم قدرة الاقتصاد المصري على التصدي لتلك التك

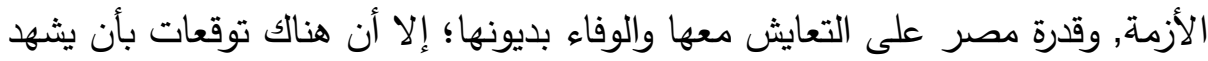
النجاح الاقتصادي الذي تحقق, توقفا في بعض القطاعات بسبب الجائحة, والذي يتمثل

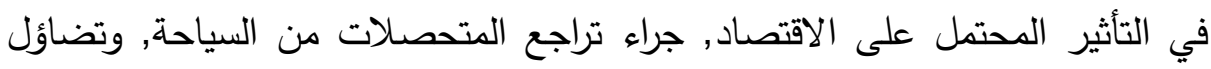
التحويلات من العاملين بالخارج, وغيرها من القطاعات, والتي قد تؤدي إلى اختلال مصادر الدخل الأجنبي بما يسبب تداعيات واسعة النطاق على الاقتصاد.

فالواقع يؤكد تأثر الاقتصاد المصري كثيرا بسبب هذه الأزمة التي ظهرت في بداية

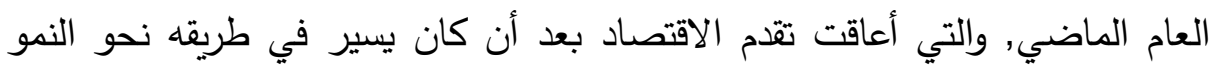

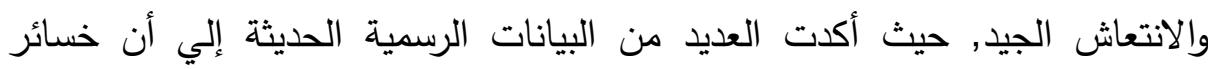
الاقتصاد المصري قد تصل الي حوالي 105 مليارات الجنيهات, ووفقا لتصريحات

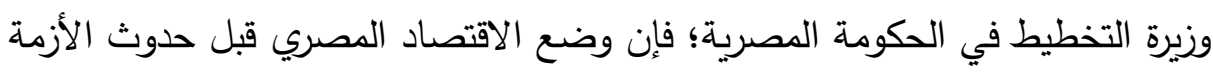

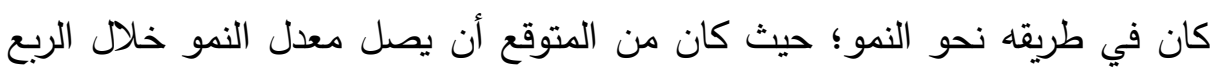

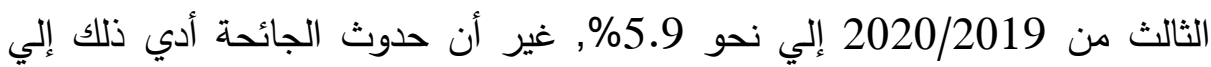
تباطؤ العديد من الأنشطة, وخاصة قطاعات السياحة والصناعة والطيران والتجارة,

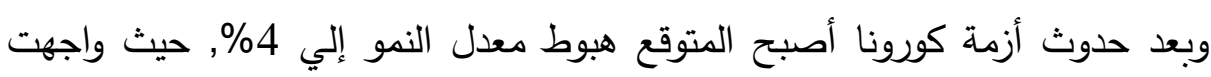

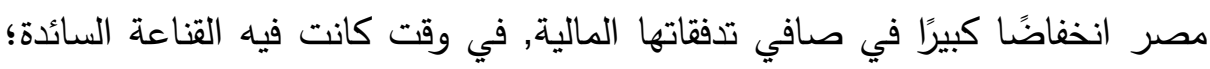
أنها كانت تسحب نفسها من عنق الزجاجة. فخسرت في هذه الأزمة دخلها من قطاع

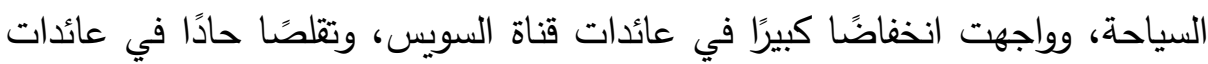
التصدير، وسط الانخفاض الحاد في أسعار النفط والغاز العالمية من 60 دولارًا للبرميل إلى ما لا يزيد عن 25 دولارًا للبرميل. إضافة إلى كل هذا، كان لانخفاض

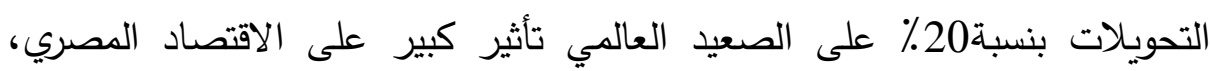


باعتباره خامس أكبر متلق للتحويلات في العالم. وتعد التحويلات والسياحة أكبر مصدرين للعملة الأجنبية لمصر ، وقد توقف الاثثان في فترة ما بعد كورونا التي سيكون من الصعب استردادها على المدى القصير. في ضوه الخسائر الهائلة التي لتئي

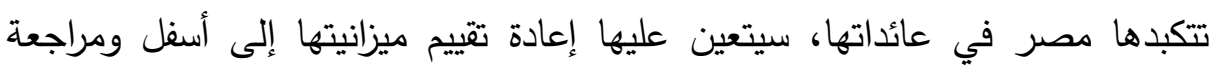

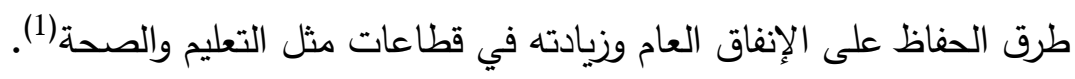
كما أضير الاقتصادي المصري بخسائر مالية باهظة نتيجة إعلان التدابير الاحترازية

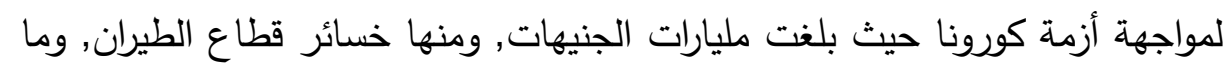
تحملته الحكومة من خسائر مالية كبيرة نتيجة إعطاء العاملين في كافة قطاعات الدولة إجازات من العمل لتقليل الكثافة في مختلف قطاعات الدولة, وكان قطاع السياحة من

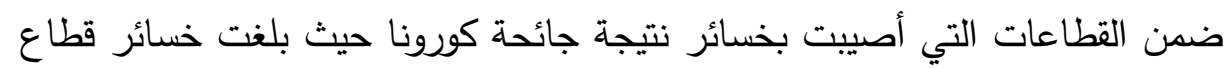
السياحة حوالي مليار دولار شهريا وفقا لما صرح به وزير السياحة والآثار المصرية,

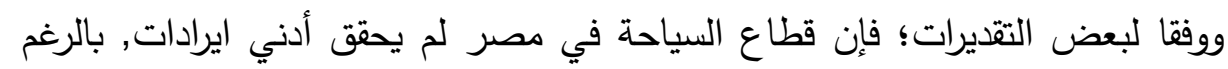
أنه في عام 2019 حقق إيرادات قدرت بحوالي 13.03 مليار دولار (2). كما تراجعت التجارة بين مصر وكثير من الدول بشكل كبير , وأشارت نشرة التجارة

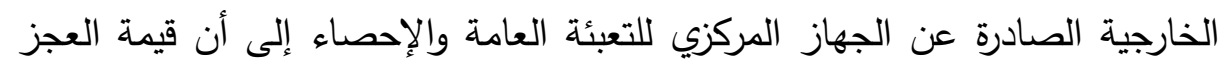
في الميزان التجاري بلغت أرقاما كبيرة بسبب الانخفاض الكبير في قيمة الواردات المصرية من بعض الدول كالصين.

\section{ثانيا: تدابير الاولة المصريـة لمواجهة الأزمـة:}

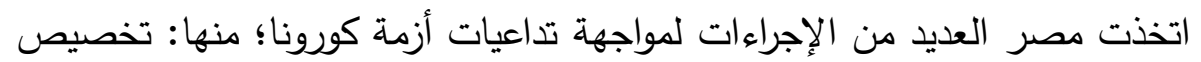

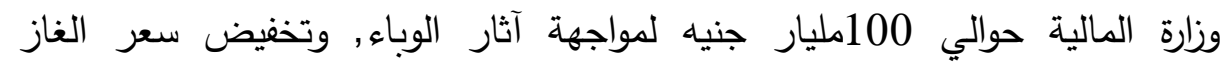
الطبيعي للصناعة إلي حوالي 4.5 دولار , وخفض أسعار الكهرباء للصناعة بحوالي

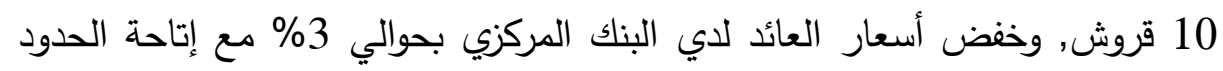

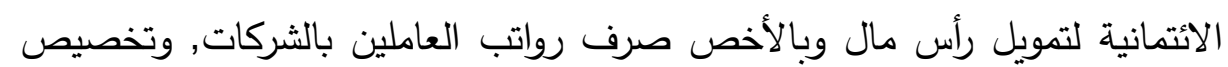

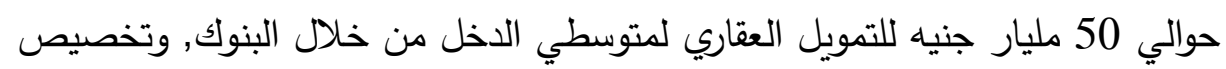


حوالي 20 مليار جنيه من البنك المركزي لدعم البورصة الدصرية, عمل مبادرة التمويل

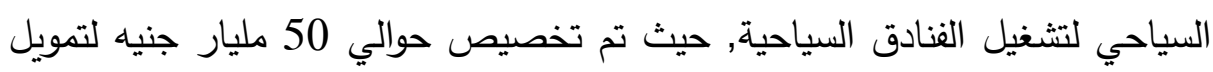
السياحة وخفض تكلفة الاقراض لتلك المبادرة الي حوالي 8\%, ودراسة القطاعات الاكثر تضررا نتيجة فيروس كورونا لتقديم الدعم اللازم لها.

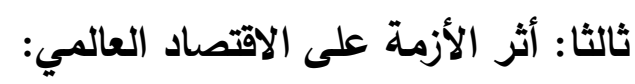

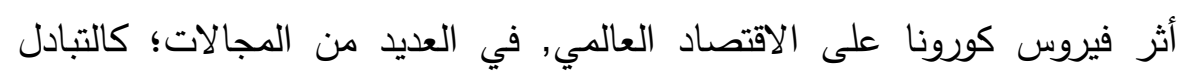

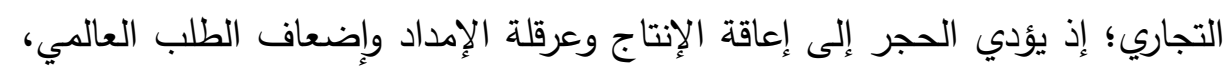

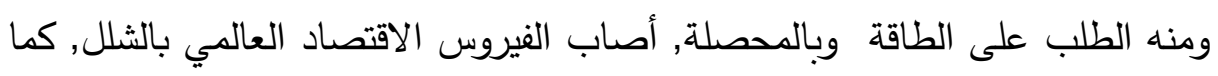

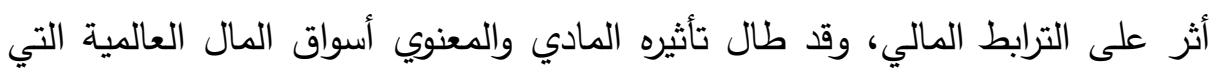

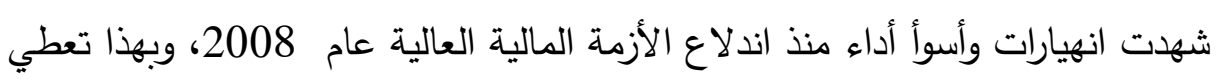

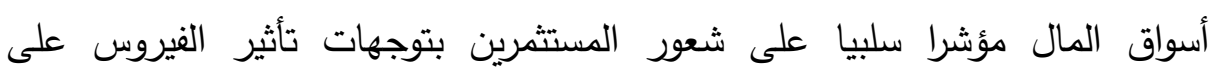

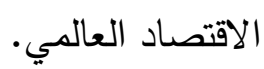
ومن القنوات التي يؤثر من خلالها فيروس كورونا على مستوى الاقتصاد العالمي:

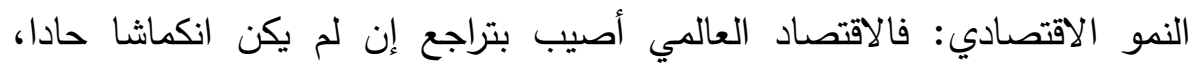

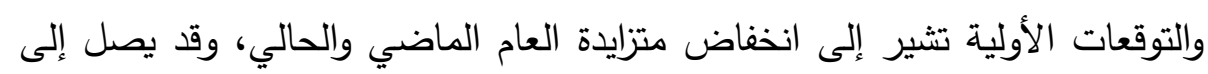

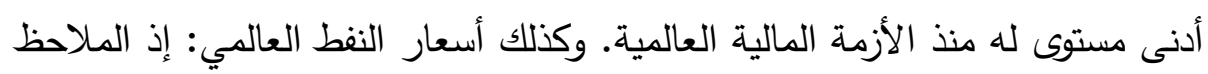

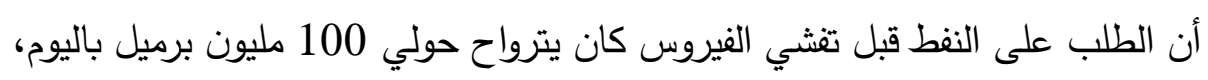
وانخفاض الطلب عليه بحوالي 15 مليون برميل.

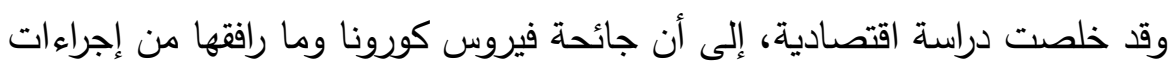

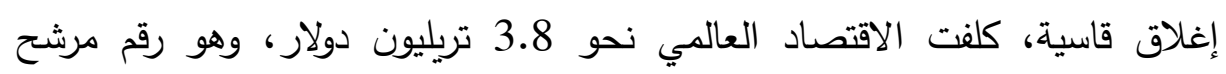

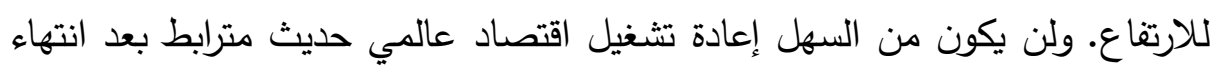

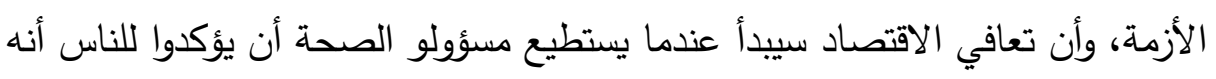

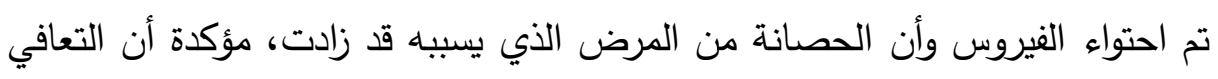

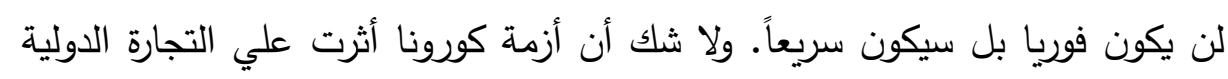
بالسلب بعد أن كانت في طريقها نحو الانتعاش الجيد (1). 


\section{المبحث الأول}

\section{انعكاس أزمة كورونا على التسوية الاتفاقية للمنازعات التجارية الأية}

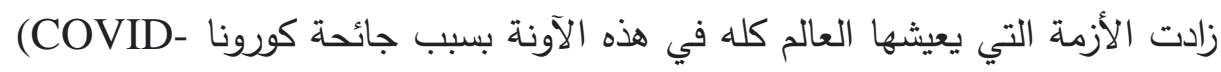
(19 من تعظيم دور التكنولوجيا وخوارزميات الذكاء الاصطناعي واستخداماته, رغبة

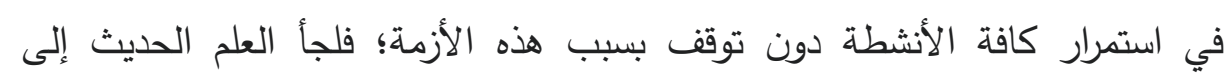

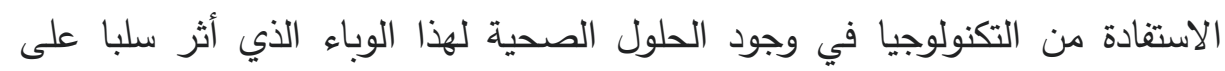
كافة الدول وكافة الأنشطة, وزادت حركة التجارة الإكترونية على المستويين الوطني

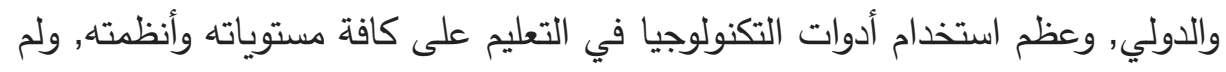

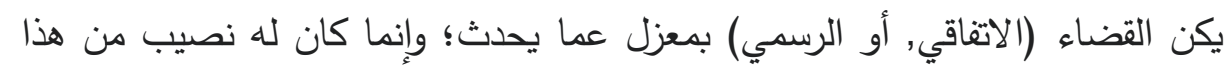
التقدم التكنولوجي الذي يعيشه العالم عبر استخدام تقنيات التكنولوجيا؛ وإن كانت بدايات التحول التقني في أنظمة القضاء سابقة على هذه الأزمة؛ إلا أن وجودها دفع

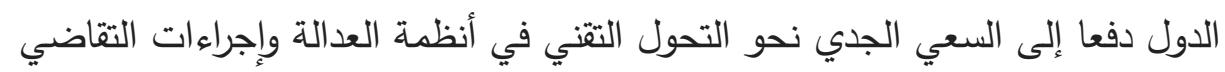
وتسوية المنازعات.

ومن أهم المنازعات التي تثور في الآونة الحالية - ومع تفاقم الأزمة وازدياد انتشار

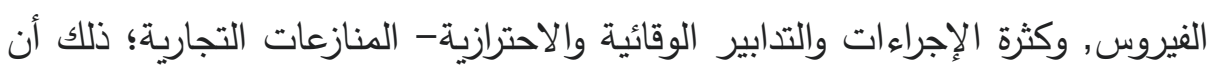
كثيرا من الأنشطة والمؤسسات التجارية عجزت عن الوفاء بالتزاماتها, إما بسبب الركود

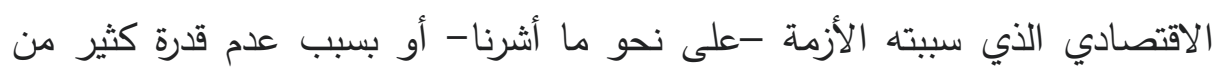

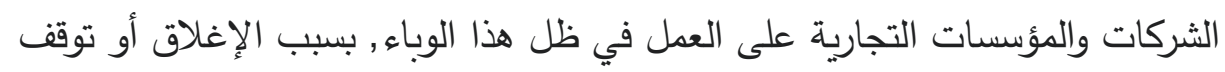
حركة النقل والثحن أو الاستيراد والتصدير , أو غير ذلك من الأسباب.

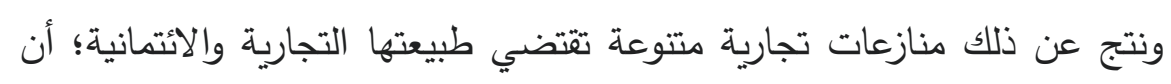
يتم تسويتها بشكل سريع يتقق مع طبيعة هذه المعاملات, ومن هنا تعاظم دور التسوية

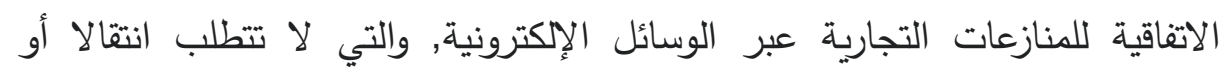
حضورا فعليا لأطراف المنازعة أو ممثليهم, ومن أهم هذه الوسائل الاتفاقية: أولا: التحكيم التجاري الإكتروني: وهو نظام قضائي إلكتروني خاص مؤداه تسوية المنازعات التي تتشأ أو من المحتمل نشوؤها إلكترونيا بين المتعاملين في مجال التجارة بموجب اتفاق بينهم يقضي نسوني 
بذلك(1). ويوفر التحكيم الإككتروني في المنازعات التجارية جملة من المزايا؛ أهمها: تقريب المسافات بين المتحاكمين, وخفض التكاليف, والسرعة في حسم المنازعة التجارية, وتجنب قضايا الاختصاص التشريعي, فضلا عن ملائمته لطبيعة المنازعات التجارية, وما يتمتع به أشخاص التحكيم من خبرة في مجال هذه المنازعات (2). ويتم إحالة النزاع على هيئة التحكيم بموجب اتفاق تحكيم إلكتروني, ثم يقدم طلب التحكيم على نموذج إلكتروني معد لذلك على موقع مركز التحكيم, وطنيا كان أم دوليا, وترفق مع الطلب المستندات والوثائق الإكترونية, التي تؤيده, ويتم الاتصال بطرفي مردي الدعوى التحكيمية إلكترونيا عبر البريد الإكتروني, أو وسيلة أخرى من وسائل الاتصال التقنية الحديثة, وتباشر جميع الإجراءات في نظر المنازعة التجارية التحكيمية التئية بصورة إلكترونية عبر استخدام وسائل تكنولوجية, كعقد الجلسات من خلال الفيديو كونفرنس, ليصدر الحكم التحكيمي في نهاية النزاع بصورة إلكترونية, ويتم إعلانه لطرفي المنازعة إلكترونيا. ولأطراف نزاع التحكيم التجاري تبادل المحررات الإكترونية

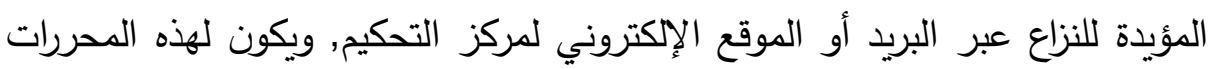
حجيتها القانونية الكاملة شأنها في ذلك شأن المحررات التقليدية. ويماثل حكم التحكيم الإكتروني الأحكام القضائية من حيث كيفية الوصول لهان لهان الحكم وذلك من خلال إجراء المداولة (الإلكترونية) بين أعضاء هيئة التحكيم

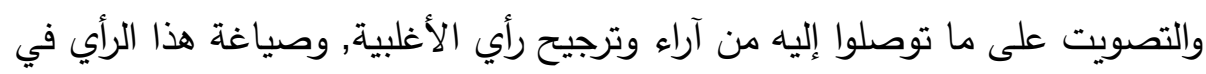

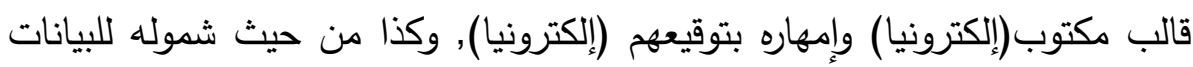
الشكلية مثل تاريخ ومكان صدور حكم التحكيم والبيانات الخاصة بهيئة التحكيم والحضور وصورة من اتفاق التحكيم وأيضا البيانات الموضوعية مثل أقوال الخصور ومستنداتهم والأسباب التي بني عليها حكم التحكيم ومنطوقه وكذلك من حيث إعلانه (إلكترونيا) لأطراف المنازعة التحكيمية.

\section{ثانيا: التوفيق الإكتروني في المنازعات التجارية:}

(1) د. إيناس الخالدي: التحكيم الإككتروني, دار النهضة العببية, القاهرة, 2009م, ص33. (2) رجاء نظام حافظ: الإطار القانوني للتحكيم الإكتروني, رسالة ماجستير , جامعة النجاح

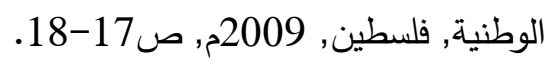


ظهر التوفيق الإكتروني كوسيلة اتفاقية لتسوية المنازعات التجارية, في العالم الافتراضي, باستخدام وسائل الاتصالات الإكترونية وفرض تواجده, فزاد الإقبال عليه

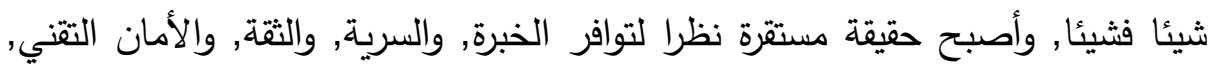

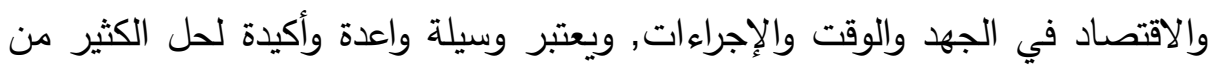
المنازعات, وذلك بعد الاعتراف التشريعي بحجية المحرر الإلكتروني والتوقيع

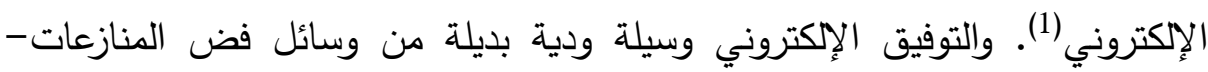

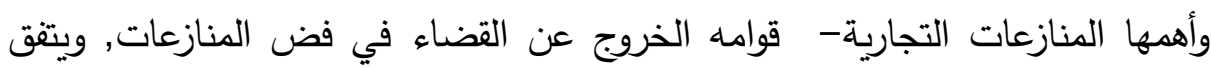
الأطراف على اللجوء إليه باتفاق توفيق شرطا كان أو مشارطة, وهو بذلك نوعا من العدالة الرضائية البديلة عن القضاء. وهو يعتمد على استعانة طرفي النزاع بطرف ثالث أجنبي تسمح له مؤهلاته الشخصية وتجربته, بالمساهمة في إيجاد حل للنزاع باتفاق تسوية, وذلك بمحاولة تقريب وجهات النظر , ووضع التسهيلات والحلول البديلة, التي يمكن التوصل إليها بناء على ما يقوم به الموفق من بحث وتحقيق, وعلى ما يقدمه الطرفان من معلومات وبيانات بخصوص ولبه النزاع, مع الأخذ في الاعتبار الظروف والملابسات المحيطة بموضوع النزاع(2). ومن حيث طبيعته الإجرائية؛ هوعملية إجرائية إرادية غير ملزمة وسرية, يقوم فيها طرف ثالث محايد ومدرب جيدا بتيسير التفاوض حول تسوية نزاع ما, ويعمل الموفق على تحسين الاتصال بين الأطراف ومساعدتهم على التعبير عن مصالحهم, وتفهر

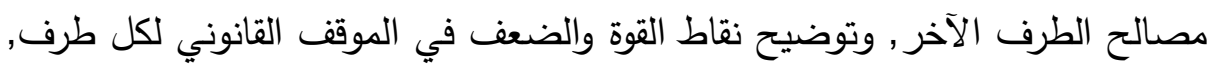
أو على تعريف الأمور القانونية والاستدلالية والمصالح المشتركة, ومجالات الاتفاق,

وطرح البدائل والخيارات, من أجل حل مرض لطرفي النزاع موضوع التوفيق(3).

ثالثا: الوساطة الإكترونية في المنازعات التجارية: تعد الوساطة الإككترونية أحد الوسائل البديلة للقضاء , باعتبارها وسيلة لحل نزاعات عقود التجارة الإلكترونية، والعقود الإلكترونية عموما، عبر استخدام الوسائل التكنولوجية (1) د. خيري عبدالفتاح البتانوني: النظام الإجرائي للتوفيق الإكتروني, دار النهضة, ص20.

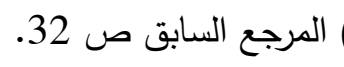

(3) د. جابر جاد نصار : التوفيق في بعض منازعات الدولة, دار النهضة العربية, القاهرة,

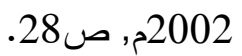


وعلى رأسها شبكة الانترنت، حيث الاستعانة من قبل الأطراف المتنازعين بوسيط لا

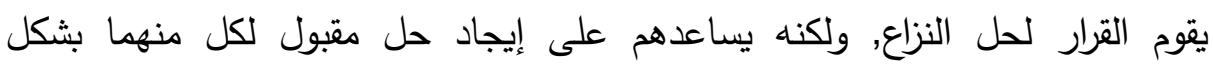
محايد(1), وهي آلية دولية معترف بها وتحمل أهمية بالغة, فهي تساهم في تسريع تسوية المنازعات التي تتشأ بسبب المعاملات المالية الإكترونية بين الأفراد الطبيعيين والمعنويين بطريقة ودية وسليمة دون اللجوء إلى القضاء الذي قد يطيل أمد التسوية, كما تساهم في قلة التكاليف والأعباء من جهد وتنقل وسفر (2), وهي بذلك وسيلك وسيلة بديلة عن قضاء الدولة في تسوية منازعات التجارة الإلكترونية, وغيرها.

وتأتي هذه الأهمية للوساطة الإكترونية باعتبارها طريق ودي لحل المنازعات

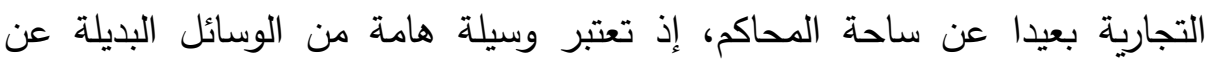

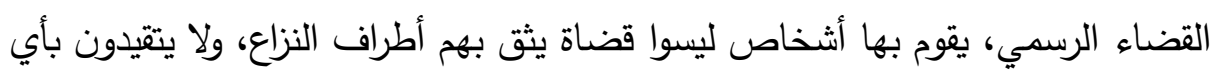
إجراءات تقوم على عدالة متأتية من اتفاق الأفراد، وذلك بالنظر لما لها من أثار لهار إيجابية، حيث تقوم على إجراءات معينة تتمثل في التقريب بين وجهات نظر طرفي

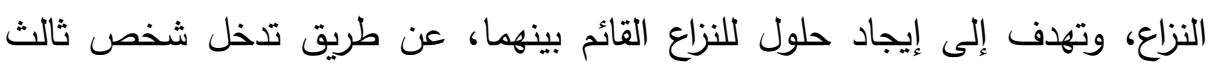
يسمى الوسيط(3). وتتم إجراءات الوساطة عبر الوسائل الإلكترونية الحديثة، باستخدام الإنترنت في

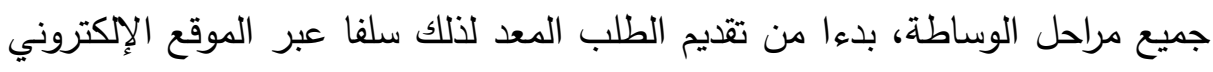

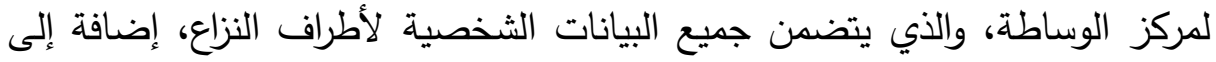

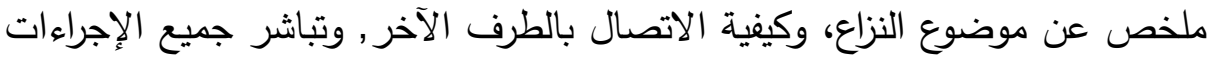
إلكترونيا, حتى يصدر اتفاق التسوية الإلكتروني ويعد سندا للتنفيذ.

(1) د. عبدالباسط جاسم محمد: تتازع الاختصاص الدولي في التعاملات التجارية الإكترونية,

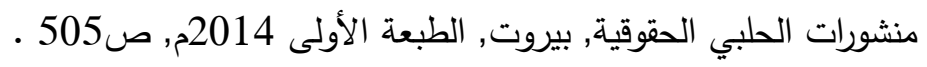
(2) لخذاري عبدالحق- آيات حمودة كهينة: العدالة البديلة لتسوية الخلافات الناشئة عن عقود التئة التجارة الإكترونية "الوساطة نموذجا", مجلة النبراس للاراسات القانونية, الدجلد 5 العدد العدانة

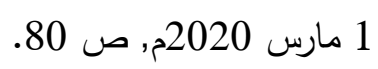

د. د. أزوا محمد, د. مسعودي يوسف: الوساطة الإكترونية كآلية لتسوية منازعات

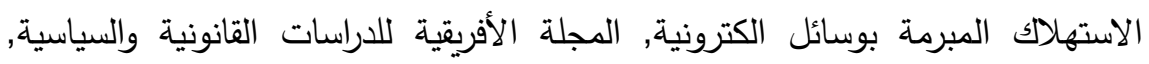

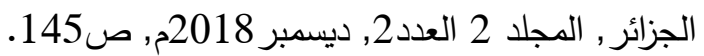


رابعا: تسوية المنازعات التجارية في إطار المنظمة العالمية للتجارة: تم إنثاء نظام خاص بتسوية النزاعات في إطار منظمة التجارة العالمية, أقر التران

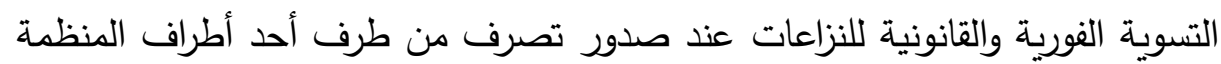

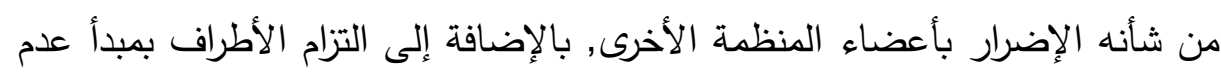

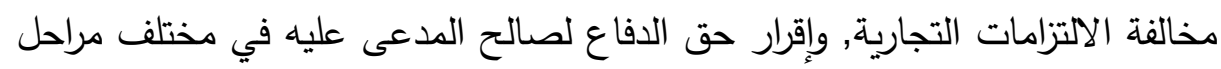

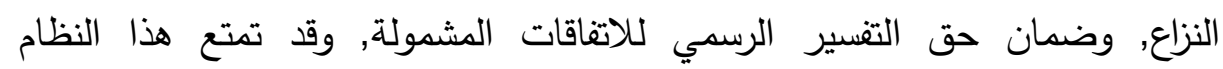
بخصائص أساسية, أهمها: الثمول وتوسيع نطاقه الذي يعتبر خطوة مهمة نحو توحيد

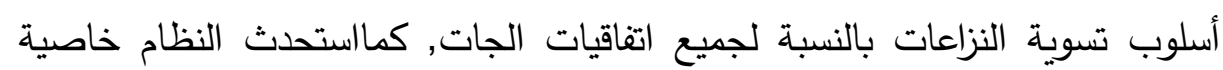
جديدة تتثثل في استئناف التقارير عن الفرق الخاصة, حيث تكون فيه تسوية النزاعات

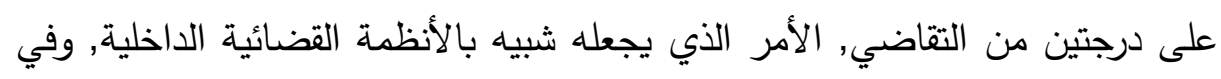

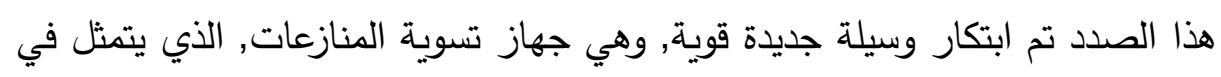

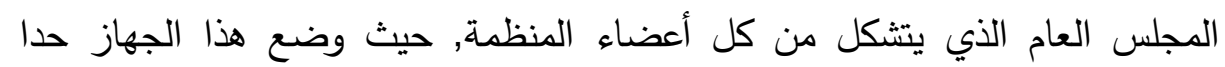
لتبادل العقوبات التجارية واتخاذ الإجراءات العقابية المنفردة بين الدول(1). وفي شأن تداعيات كورونا على تسوية المنازعات التجارية, أصدرت غرفة التجارة

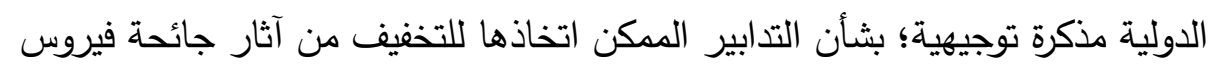

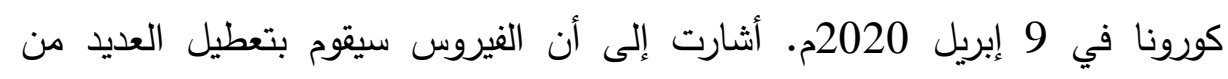

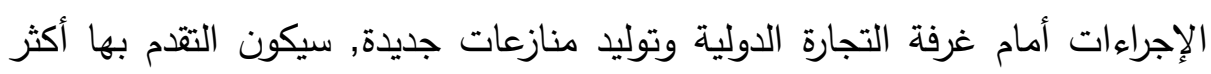

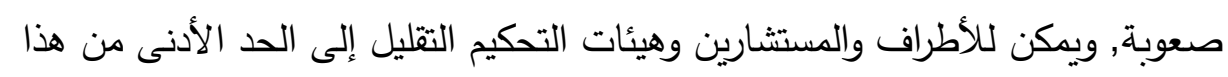

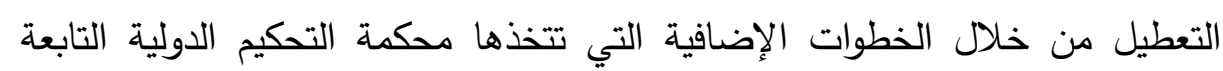
لغرفة التجارة الدولية لتبسيط عملياتها الداخلية.

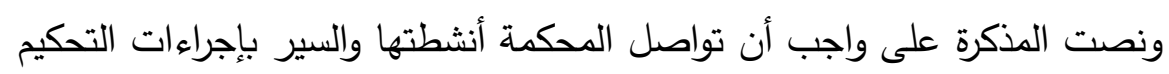

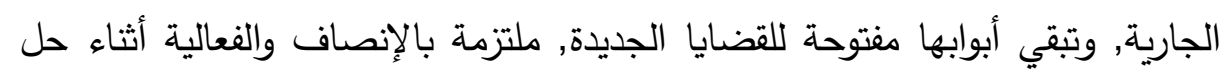
المنازعات, وأشارت الدذكرة إلى أن اعتبارات الصحة والسلامة بالإلإضافافة إلى القيود

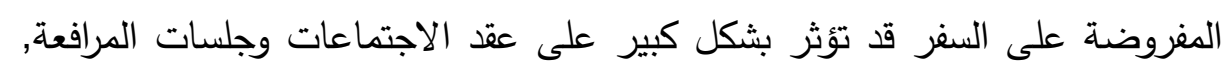
ومن ثم سمحت بعقد جلسات افتراضية من خلال الاتصالات الإلكترونية.

(1) نوال شعلان: تسوية النزاعات في إطار المنظمة العالمية للتجارة, رسالة ماجستير , كلية

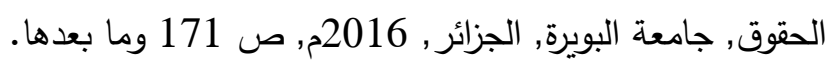




\section{المبحث الثاني}

\section{إنعكاس أزمة كورنا على التسوية القضائية للمنازعات التجارية}

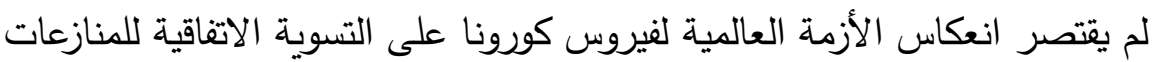
التجارية عبر التحول إلى الوسائل الإكترونية؛ وإنما انعكست الأزمة على التسوية القضائية لهذه المنازعات, من خلال التحول التقني نحو نظم التقاضي الإلكتروني في الإنى العديد من الدول؛ وإن كانت بوادر هذا التحول سابقة للأزمة؛ إلا أن حدوث الأزمة وآثارها أدى الى زيادة فعالية نظام التقاضي الإكتروني والمحاكم عن بعد.

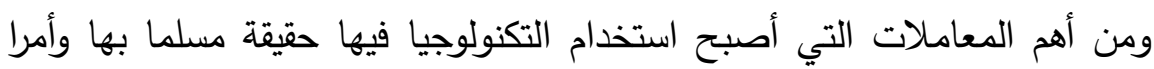
واقعيا مفروضا وملموسا؛ المعاملات التجارية, ولا شك أن ما تثيره هذه المعاملات من

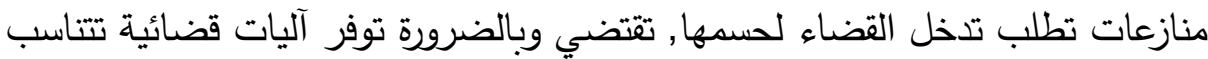
مع طبيعة هذه المعاملات؛ إذ لا تجدي معها ومع متطلباتها السريعة؛ الإجراءات القضائية التقليدية التي تعتمد على المستندات والأوراق الخطية ووسائل الإثبات التقليدية, وغير ذلك؛ ومن هنا سعت الأنظمة القضائية إلى تطوير آلياتها وإجراءاتها عبر أنظمة التكنولوجيا والتقنيات الحديثة, لتتحول الإجراءات تقنيا من النظام التقليدي إلى النظام الإكتروني, وبهذا تكون آليات التقاضي وإجراءاته قد أصبحت أكثر تتاغما وملائمة لما عليه منازعات التجارة الإلكترونية من تطور تقني. لإئرئ

ونظرا للدور المهم للمكمة الاقتصادية؛ فإن المشرع المصري عمد إلى تعديل تشريعي في إجراءات التقاضي أمامها, بحيث تباشر الإجراءات إلكترونيا, وعدم الاكتفاء بالإجراءات التقليدية, حيث لم تعد هذه الأخيرة مناسبة لطبيعة الدعاوى التي لهي تختص بها هذه المحكمة؛ ومن ثم أصدر القانون رقم (146) لسنة 2019, مستجيبا لهاء بمقتضاه لمقتضيات التقدم التكنولوجي. 


\section{الخاتمة}

أولا النتائَج: - n

1- أثرت أزمة كورنا بشكل مباشر وكبير على النظام الاقتصادي في مصر والعالم كله, وبشكل أدى إلى تراجع معدلات النمو والانخفاض في معدلات الطلب, وبما أرهق الاقتصاد الوطني والعالمي جراء التدابير الوقائية, وحالة الإغلاق التئي

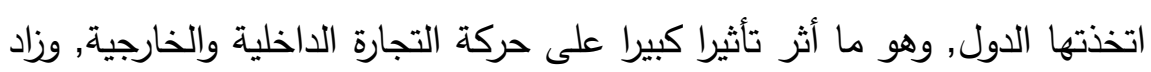

$$
\text { من نسبة المنازعات التجارية. }
$$

2- انعكست الأزمة بالتبعية لذلك على المنازعات التجارية ذاتها وآليات تسويتها؛ فاتجهت الجهود إلى إيجاد آليات لتسوية هذه المنازعات في ظل ما يشهده العالم من توقف حركة النقل وصعوبة اجتماع الأطراف في مكان واحد. 3- كان من آثار أزمة كورونا أن تعاظم دور الوسائل الإككترونية في تسوية المنازعات

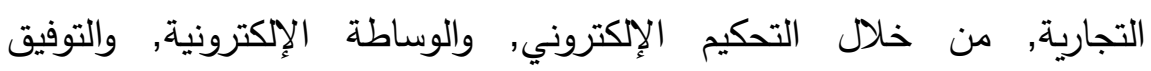

$$
\text { الإلكتروني. }
$$

4- لم يقتصر الأمر على التحول التقني للأنظمة الاتفاقية؛ وإنما امتد ليشمل أنظمة

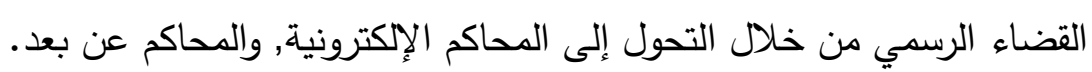
ثانيا: التوصيات:

1- نوصي المشرع المصري بتعديل قانون التحكيم المصري, بما يواكب التطورات التقنية التي يشهدها الواقع المعاصر , بالتحول للتحكيم الإكتروني. 2- تعديل قانون المرافعات المدنية والتجارية بما يسمح بنظم التقاضي الإلكتروني. 3- إنشاء دوائر قضائية متخصصة بنظر المنازعات التجارية عبر الوسائل الإلكترونية, على غرار المعمول به في المحكمة الاقتصادية. 